\title{
Utility of Total Desmosine as Biomarker for Chronic Obstructive Pulmonary Disease Patients
}

\author{
Adel Attia ${ }^{1 *}$, Ashraf Abd El Halim ${ }^{1}$, Eman Shebl ${ }^{1}$ and Ahmed Ali ${ }^{2}$ \\ ${ }^{1}$ Department of Chest Diseases, Faculty of Medicine, Zagazig University, Egypt \\ ${ }^{2}$ Departments of Pulomonology and Chemical Pathology, King Fahad Specialist Hospital, KSA
}

\begin{abstract}
Matrix degradation is a key feature of COPD, leading to lung destruction, emphysema and impaired pulmonary function. Desmosine and isodesmosine are elastin-derived cross linked amino acids whose urine levels are considered representative of elastin breakdown. However, there is a lack of biomarkers to measure disease activity and disease progression in COPD.
\end{abstract}

Aim: This study was done to determine the utility of urine and blood desmosine as a biomarker in diagnosis of COPD patients and to evaluate their relationship with lung function parameters.

Methods: The urine and blood desmosine levels were measured using validated isotope dilution liquid chromatography tandem mass spectrometry methods in 151 subjects including 101 COPD patients and 50 healthy control subjects.

Results: The COPD patients had higher levels of $u$-desmosine and b-desmosine compared with healthy smokers and non-smokers. There was statistically significant difference in the mean levels of u-desmosine and b-desmosine between the different severity groups of the COPD patients. After adjustments for age, sex, and BMI; the concentrations of $u$-desmosine and b-desmosine were significantly correlated with FEV1s $\%$ and DLCO $\%(p<0.05)$ among the COPD patients. The elevation of b-desmosine levels above cutoff of $0.30 \mathrm{ng} / \mathrm{ml}$ was not specific for COPD and was found in $69 \%$ of all COPD patients. This cutoff value had a diagnostic sensitivity of $71 \%$ and specificity of $53 \%$.

Conclusions: This study has demonstrated that both $u$-DES and b-DES levels were significantly elevated among COPD patients. Also, u-DES or b-DES levels are correlated with COPD severity and some lung function parameters.

Keywords: Desmosine; Biomarker; Chronic Obstructive Pulmonary Disease (COPD)

\section{Introduction}

Chronic Obstructive Pulmonary Disease (COPD) is a major public health problem. It is the fourth leading cause of chronic morbidity and mortality in the United States, and is projected to rank fifth in 2020 in burden of disease caused worldwide, according to a study published by the World Health Organization [1]. COPD is characterized by a specific pattern of inflammation involving neutrophils, macrophages, and lymphocytes. These cells release inflammatory mediators and enzymes that interact with structural cells in the airways and lung parenchyma leading to destruction of lung parenchyma [2]. Matrix degradation is a key feature of COPD, leading to lung destruction, emphysema and impaired pulmonary function. The elasticity and resilience of the lungs are mainly provided by elastin, which is synthesized as a soluble precursor, tropoelastin [3]. Elastin synthesis involves secretion of tropoelastin, which is a $72-\mathrm{KD}$ monomer, into the extracellular space by elastin-synthesizing cells, then cross-linking of monomers by two amino acids, Desmosine and Isodesmosine (DI) [4]. The cross-linking transforms the soluble tropoelastin precursor to the insoluble crosslinked mature elastic fiber. DI occurs only in mature elastin, and their presence in body fluids is a chemical indicator of degradation of mature elastic fibers [5]. They are released, either in free form or conjugated to peptides, as a result of elastin degradation, and can be found in sputum, blood and urine [6,7]. Classification of COPD is usually based on the severity of airflow obstruction, as assessed using forced expiratory volume in $1 \mathrm{~s}$ (FEV1) [1]. However, there is a lack of biomarkers to measure disease activity and disease progression in COPD [8]. Desmosine and isodesmosine have been proposed as biomarkers of lung matrix degradation in COPD [9-11].

\section{Materials and Methods}

The current study included 2 groups:

\section{Group 1}

It included 101 COPD patients (53 men and 48 women) with a mean age of $61.0 \pm 4.60$ years This group included 56 patients with stable COPD and 45 patients with COPD with exacerbation seen at the Pulmonology Department of King Fahad Hospital in Dammam, Kingdom of Saudi Arabia. The study was approved by the Ethics and Research Committee. All patients and control subjects gave their written informed consent before participating in the study. The diagnosis of COPD was established by clinical symptoms, physical examination, chest radiography and pulmonary function test according to the guidelines of GOLD 2013. The COPD subjects were classified into (stages I-IV) on the basis of their post-bronchodilator forced expiratory volume in one second (FEV1)/Forced Vital Capacity (FVC) and FEV1 $\%$ predicted. FEV1/FVC was $<70 \%$ and their FEV1 fell into set bands (stage 1: FEV1 $\geq 80 \%$; stage 2:50\% $\geq$ FEV1<80\%; stage 3:30\% $\geq$ FEV $1<50 \%$; stage $4: F E V 1<30 \%)$.

Stable chronic obstructive pulmonary disease: Stable COPD is defined by the absence of any exacerbation for 3 months preceding the study [12].

Chronic obstructive pulmonary disease exacerbation: The American Thoracic Society (ATS) and European Respiratory Society

${ }^{*}$ Corresponding author: Adel Attia, Department of Chest Diseases, Faculty of Medicine, Zagazig University, Egypt, E-mail: adelattia68@yahoo.com

Received June 26, 2013; Accepted July 29, 2013; Published July 31, 2013

Citation: Attia A, Abd El Halim A, Shebl E, Ali A (2013) Utility of Total Desmosine as Biomarker for Chronic Obstructive Pulmonary Disease Patients. J Pulm Respir Med 3: 152. doi:10.4172/2161-105X. 1000152

Copyright: (c) 2013 Attia A, et al. This is an open-access article distributed under the terms of the Creative Commons Attribution License, which permits unrestricted use, distribution, and reproduction in any medium, provided the original author and source are credited. 
(ERS) defines an exacerbation as an acute change in a patient's baseline dyspnea, cough, or sputum that is beyond normal variability, and that is sufficient to warrant a change in therapy [13].

\section{Group 2}

It included 50 control subjects ( 33 men and 17 women) with a mean age of $59.6 \pm 6.1$ years. This group included 25 non smokers and 25 current smokers (over 10 pack years). They were without any disease and had normal spirometry. The patients and control subjects were matched for age, sex and Body Mass Index (BMI).

Methods: All subjects participating in the study were evaluated with a complete history, physical examination, chest $\mathrm{x}$-ray, arterial blood gases and pulmonary function tests (PFT). Spirometry was performed according to American Thoracic Society guidelines 2005. Transfer factor of the lung for carbon monoxide (DLCO\%) was measured using the body plethysmography technique (CareFusion Inc., San Diego, CA, USA) and corrected for hemoglobin and carboxy hemoglobin [14].

\section{Measurement of urine and blood desmosine}

Sampling: The stable COPD patients had spotted urine and blood samples collected during a checkup at OPD visit. The COPD with exacerbation patients had urine and blood samples collected during hospital admission. Healthy subjects had spotted urine and blood samples. Urine samples were collected and frozen at $-80^{\circ} \mathrm{C}$ until analysis. Similarly blood samples were separated and sera were collected and frozen at $-80^{\circ} \mathrm{C}$ until analysis (Table 2).

Measurements: Urinary creatinine concentration was measured for each urine sample using assay kits purchased from Abcam Inc. (330 Cambridge Science Park, Cambridge CB4 OFL, UK). U-desmosine

\begin{tabular}{|l|c|c|c|c|}
\hline & \multicolumn{2}{|c|}{ Control group } & \multicolumn{2}{c|}{ COPD Patients group } \\
\cline { 2 - 5 } & $\begin{array}{c}\text { Healthy non } \\
\text { smoker } \\
\text { (N=25) }\end{array}$ & $\begin{array}{c}\text { Healthy } \\
\text { smokers } \\
\text { (N=25) }\end{array}$ & $\begin{array}{c}\text { Stable COPD } \\
\text { (N=56) }\end{array}$ & $\begin{array}{c}\text { Exacerbated } \\
\text { COPD (N=45) }\end{array}$ \\
\hline Gender (M/F) & $13 / 12$ & $20 / 5$ & $29 / 27$ & $24 / 21$ \\
Age & $58 \pm 7$ & $59 \pm 9$ & $59 \pm 8$ & $62 \pm 6$ \\
BMI & $27 \pm 3$ & $27 \pm 2$ & $27 \pm 4$ & $26 \pm 2$ \\
Smoking History & 0 & 25 & 16 & 11 \\
Current & 0 & 0 & 32 & 25 \\
Ex-smoker & 25 & 0 & 8 & 9 \\
Non-smoker & $103 \pm 9.7$ & $98 \pm 6.3$ & $76.21 \pm 10.96$ & $38 \pm 10.25$ \\
FEV1\% of predicted & $103 \pm 10.6$ & $101 \pm 8.4$ & $98 \pm 13.9$ & $87 \pm 21.1$ \\
FVC\% of predicted & $97.45 \pm 7.6$ & $96.23 \pm 5.7$ & $92.45 \pm 15.85$ & $73.67 \pm 8.65$ \\
DLCO \% of predicted & & & & \\
\hline
\end{tabular}

Table 1: Demographic data for the subjects included in this study. assays were carried out using validated isotope dilution liquid chromatography tandem mass spectrometry (LC-MS/MS) methods (The 4000 QTRAP $^{\circ}$ LC/MS/MS System, AB SCIEX, Framingham, MA 01701, USA) The u-DES levels were expressed as u-desmosine concentration normalized to the urinary creatinine concentration [15]. Similarly b-desmosine concentration was analyzed using a modified assay with 10 times the lower limit of quantification. Desmosine assay kits were purchased from Elastin Products Company Inc. (Owensville, Missouri, USA) [16].

\section{Statistical analysis}

Statistical analysis was performed with the Statistical Package for the Social Sciences, version 16 for Windows (SPSS Inc., Chicago, IL, USA). The difference between groups were tested by one-way analyses of variance (ANOVA) test. Correlations were investigated by means of the Pearson correlation coefficient. Values of $p<0.05$ were considered statistically significant.

\section{Results}

Our study found that both $\mathrm{u}$-desmosine and b-desmosine levels are statistically significantly correlated with age. These correlations were observed in all subjects included in this study (for urine and blood desmosine respectively: COPD patients; $\mathrm{r}=0.479$ and 0.622 Control subjects; $\mathrm{r}=0.459$ and 0.394$)(\mathrm{P}<0.01$ for all groups $)$.

In this study, the patients with stable COPD excreted a higher level of u-desmosine $(13.19 \pm 2.54)$ compared with healthy smokers $(10 \pm 2.91)$ and non-smokers $(8 \pm 2.101)(\mathrm{p}<0.05)$. Similar results were found among COPD patients with exacerbation $(18.51 \pm 2.074)(\mathrm{p}<0.01)$. U-desmosine levels didn't show a statistically significant difference between healthy smokers and healthy non-smokers $(\mathrm{p}>0.05)$. Also, no statistically significant difference was found between non-smokers, current smokers and ex-smokers among the COPD patient groups ( $\mathrm{p}>0.05)$.

Our work detected that the b-desmosine levels were statistically significantly higher among the patients with stable $(0.29 \pm 0.045)$ and exacerbated COPD $(0.34 \pm 0.034)$ in comparison with healthy smoker $(0.22 \pm 0.061)$ and non-smokers subjects $(0.20 \pm 0.045)(\mathrm{p}<0.01)$. The b-desmosine levels didn't show a statistically significant difference between healthy smokers and healthy non-smokers $(p>0.05)$.

We found that the $\mathrm{u}$-desmosine and $\mathrm{b}$-desmosine were statistically significantly higher among exacerbated COPD patients $(18.51 \pm 2.074$ and $0.34 \pm 0.034$ respectively) in comparison with stable COPD patients $(13.19 \pm 2.54$ and $0.29 \pm 0.045$ respectively $)(p<0.01)$.

\begin{tabular}{|c|c|c|c|c|c|c|}
\hline & \multicolumn{3}{|c|}{ Control group } & \multicolumn{3}{|c|}{ COPD Patients group } \\
\hline & $\begin{array}{l}\text { Healthy non smoker } \\
\qquad(\mathrm{N}=25)\end{array}$ & $\begin{array}{l}\text { Healthy smokers } \\
\qquad(\mathrm{N}=25)\end{array}$ & $\begin{array}{l}\text { Total } \\
(\mathrm{N}=50)\end{array}$ & $\begin{array}{l}\text { Stable COPD } \\
(\mathrm{N}=56)\end{array}$ & $\begin{array}{c}\text { Exacerbated COPD } \\
(\mathrm{N}=45)\end{array}$ & $\begin{array}{l}\text { Total COPD } \\
(\mathrm{N}=101)\end{array}$ \\
\hline $\begin{array}{l}\text { Urine desmosine ( } \mathrm{ng} / \mathrm{mg} \text { creatinine) } \\
\text { Blood desmosine }(\mathrm{ng} / \mathrm{ml})\end{array}$ & $\begin{array}{c}8 \pm 2.101 \\
0.20 \pm 0.045\end{array}$ & $\begin{array}{c}10 \pm 2.91 \\
0.22 \pm 0.061\end{array}$ & $\begin{array}{c}9.42 \pm 1.37 \\
0.21 \pm 0.016\end{array}$ & $\begin{array}{l}13.19 \pm 2.54^{* *} \\
0.29 \pm 0.045^{* *}\end{array}$ & $\begin{array}{l}18.51 \pm 2.074^{*+*+} \\
0.34 \pm 0.034\end{array}$ & $\begin{array}{l}15.56 \pm 3.53^{*} \\
0.31 \pm 0.038^{*}\end{array}$ \\
\hline
\end{tabular}

$P$ value $<0.001$ (statistically significant difference between COPD patients and control subjects 0 .

${ }^{*} \mathrm{P}$ value $<0.05$ (statistically significant difference between the stable patients and

control subjects)

${ }^{* * *} \mathrm{P}$ value $<0.01$ (statistically significant difference between exacerbated COPD and other groups).

Table 2: Urine and blood desmosine mean levels among the subjects included in this study.

\begin{tabular}{|l|c|c|c|}
\hline & \multicolumn{1}{|c|}{$\begin{array}{c}\text { Mild } \\
\mathbf{N}=\mathbf{3 2}\end{array}$} & $\begin{array}{c}\text { Moderate } \\
\mathbf{N}=\mathbf{2 7}\end{array}$ & $\begin{array}{c}\text { Severe } \\
\mathbf{N = 2 3}\end{array}$ \\
\hline Urine Desmosine $(\mathrm{ng} / \mathrm{mg}$ creatinine) & $12.28 \pm 2.67$ & $14.59 \pm 1.76$ & $17.52 \pm 1.65^{*}$ \\
Blood Desmosine $(\mathrm{ng} / \mathrm{ml})$ & $0.27 \pm 0.021$ & $0.30 \pm 0.014$ & $20.11 \pm 1.45^{* *}$ \\
\hline
\end{tabular}

* $P$ value $<0.05$ significant difference between mild and severe COPD patients.

" $P$ value $<0.05$ significant difference between very severe COPD patients and other severity group patients.

Table 3: Desmosine mean levels in relation to severity of COPD. 


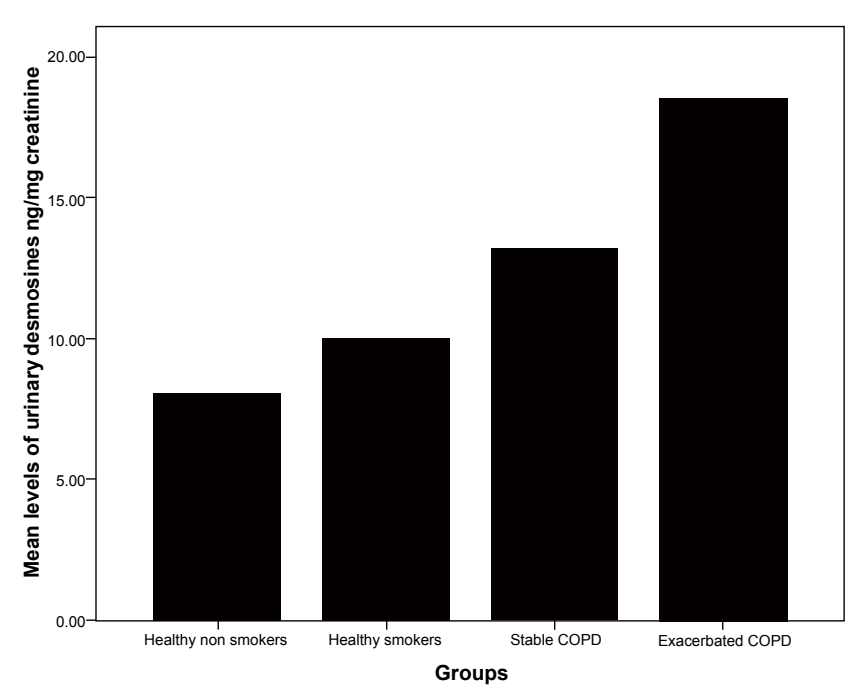

Figure 1: Urine desmosine mean levels among the subjects included in this study.

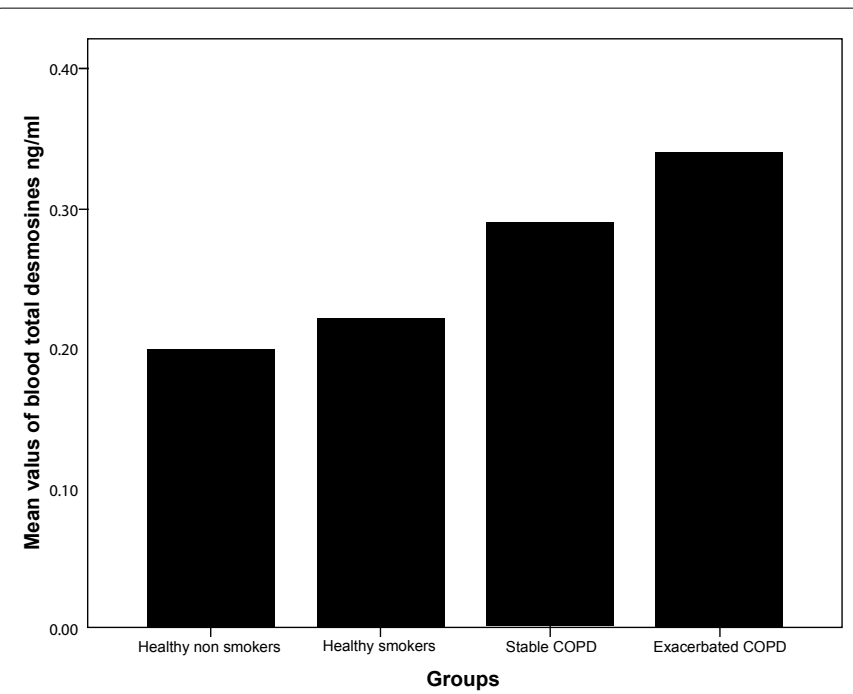

Figure 2: Blood desmosine mean levels among the subjects included in this study.

In this work, the levels of $\mathrm{u}$-desmosine and b-desmosine were found to be positively correlated $(\mathrm{r}=0.679)$ among all COPD patients (stable COPD patients and exacerbated COPD patients) $(\mathrm{p}<0.01)$.

In this work the mean levels of $\mathrm{u}$-desmosine and $\mathrm{b}$-desmosine were statistically significantly higher in patients with severe COPD (17.52 \pm 1.65 and $0.31 \pm 0.013$ respectively) compared with those with mild COPD $(12.28 \pm 2.67$ and $0.27 \pm 0.021$ respectively) $(\mathrm{p}<0.05)$ (Table 3$)$. Also, the mean levels of $\mathrm{u}$-desmosine and $\mathrm{b}$-desmosine were statistically significantly higher in patients with very severe COPD $(20.11 \pm 1.45$ and $0.36 \pm 0.038$ respectively) in comparison with other severity group patients $(\mathrm{p}<0.05)$. Also, $\mathrm{u}$-desmosine and $\mathrm{b}$-desmosine were significantly and inversely correlated with FEV1\% ( $r=-0.828$ and -0.795 respectively $)$ and DLCO \% ( $\mathrm{r}=-0.564$ and -0.708 respectively $)(\mathrm{p}<0.01)$.

In this study we found that the elevation of b-desmosine levels was found in $69 \%$ of all COPD patients (stable COPD and exacerbated COPD) based on a cutoff of $0.30 \mathrm{ng} / \mathrm{ml}$. The area under the curve (AUC) for b-desmosine was 0.612 and $95 \%$ confidence interval $(\mathrm{CI})$ was 0.451 -
0.731 using the Youden index, the cutoff value for b- desmosine to predict COPD $0.30 \mathrm{ng} / \mathrm{ml}$.This cutoff value had a diagnostic sensitivity of $71 \%$ and specificity of $53 \%$ (Figures 1-6).

\section{Disccusion}

Our study found that both u-DES and b-DES levels are statistically significantly correlated with age. These correlations were observed in

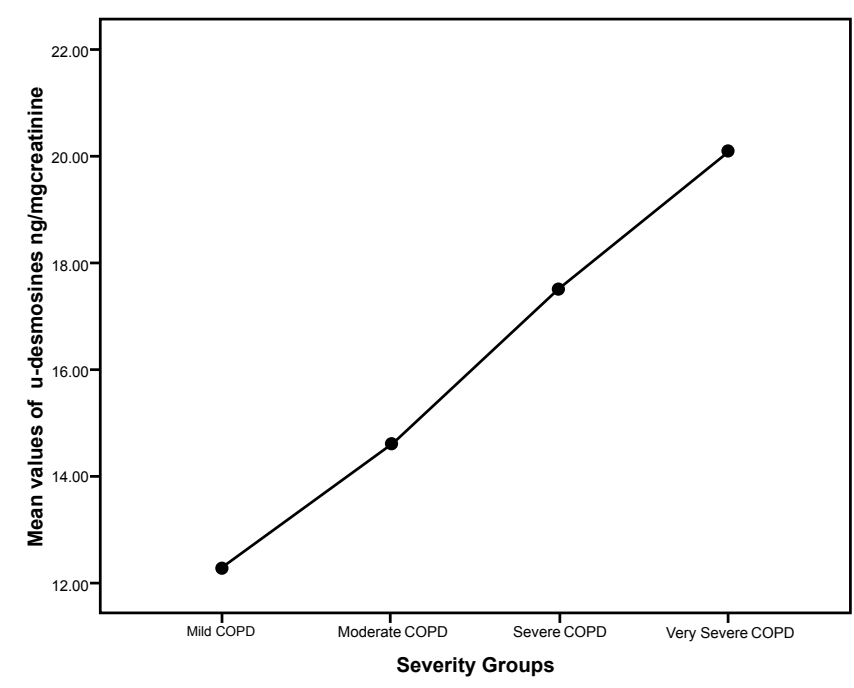

Figure 3: Urine desmosine mean levels in relation to severity of COPD.

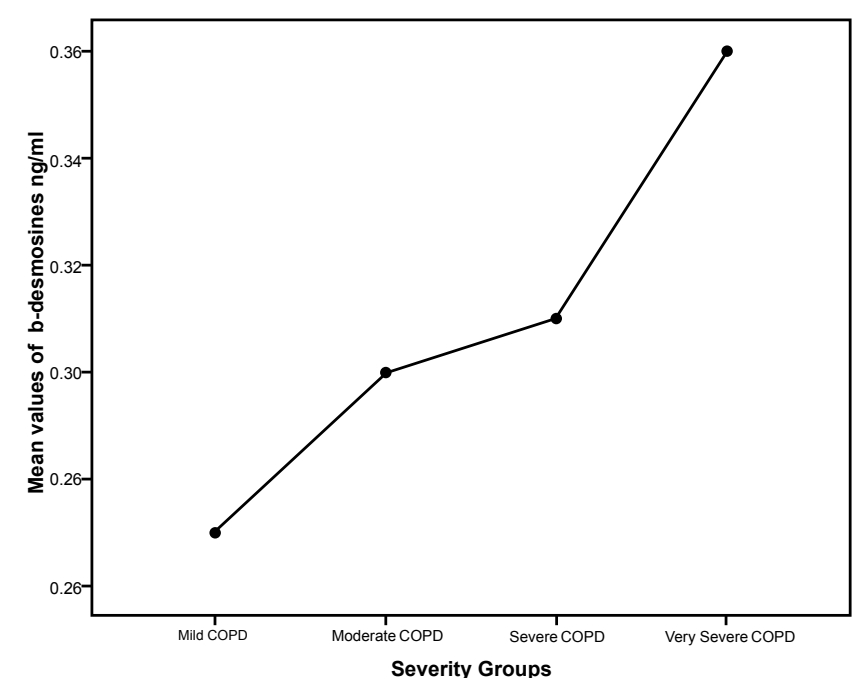

Figure 4: Blood desmosine mean levels in relation to severity of COPD.

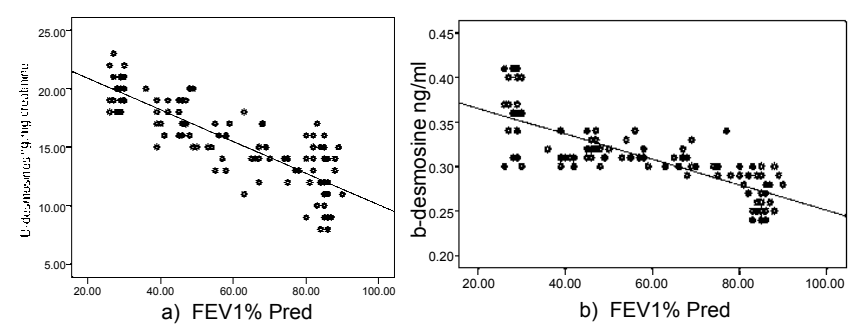

Figure 5: Scatterplot with regression slopes of log: a) Urine desmosine and b) Blood desmosine in relation to forced expiratory volume in $1 \mathrm{~s}$ (FEV1)\%. 


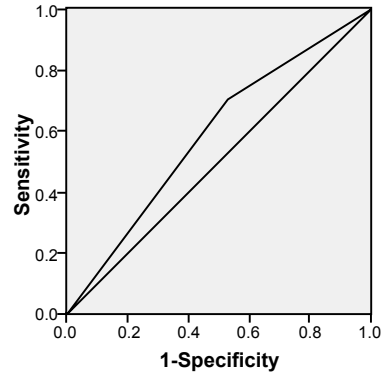

Figure 6: ROC curve was constructed by plotting the sensitivity versus 1 specificity at cutoff value $0.30, b$ - desmosine has AUC with value 0.612 with non significant value.

all subjects included in this study.These results are consistent with that of other investigators. Stone et al. [10] reported a positive correlation between age and u-desmosine excretion (creatinine normalized) in a small group. Also, Linderberg et al. [16] demonstrated a strong correlation between age and either $\mathrm{u}$ - or b-desomsine. These results are explained by with the finding that increased elastolysis and degradation of elastin are features of normal ageing [17] and the concept of "senile emphysema", normal physiological ageing of the lung associated with dilatation of alveoli, enlargement of airspaces and loss of supporting tissue for peripheral airways [18].

In our work, the levels of u-desmosine and b-desomsine, (after adjustment for age, sex and BMI) didn't show a statistically significant difference between healthy smokers and healthy non-smokers. Also, no statistically significant difference was found between nonsmokers, current smokers and ex-smokers among the COPD patient groups. Huang et al. [19] demonstrated no correlation between either u-desmosine or b-desmosine and smoking. However, reported smoking was significantly associated with levels of u-desmosine and non significantly with b-desmosine, after adjustment for age, sex and BMI [17]. Explanations for the different results may be due to variation of the sample sizes and varying correction for other, potentially confounding factors. There is another explanation for this difference in results; although, smoking is the main risk factor for COPD, not all smokers will develop COPD. The variation in the genetic and environmental factors among smokers will determine the harmful effect of the smoking on the lung.

We found that the $\mathrm{u}$-desomsine and b-desomsine were statistically significantly higher among exacerbated COPD patients in comparison with stable COPD patients. These results suggest that these COPD patients with exacerbations may have increased elastin degradation and may excrete more elastin-derived cross-linked amino acids than patients with stable COPD. This probably reflects the increased burden of neutrophils within the lungs, occurring during an acute exacerbation of COPD $[20,21]$ which is responsible for the purulence of the sputum and the high concentration of sputum serine proteases such as neutrophil elastase [22]. Thus, it may be supposed that the increased desomsine excretion in an exacerbation of COPD is the result of acute damage to elastin in bronchial and bronchiolar walls by neutrophil elastase, adding to the "baseline" elastin degradation found in stable COPD. The two COPD populations in the present study did not differ in terms of age or smoking history, although a significantly lower level of respiratory function was found in the group with the exacerbation. It is likely that this difference was due to the increased pulmonary inflammation during the acute exacerbation $[17,23,24]$.

In this work, we investigated the association between $\mathrm{u}$ - desomsine and b-desmosine and some lung function measures (FEV1\% and DLCO\%). The u-desmosine and b-desmosine were significantly and inversely correlated with FEV1\% and DLCO \% after adjustment for age, BMI, sex and smoking status. Gottlieb et al. [24] and Linderberg et al. [16] found significantly higher u-desmosine excretion in lower FEV1, and a significant correlation between desmosine excretion and lower FEV1. Another study by Viglio et al. [25] showed a correlation between u-desmosine and FEV1 \% in a group of patients with destructive lung disease (cystic fibrosis, bronchiectasis, COPD and a1-antitrypsin deficiency), In contrast, Boutin et al. [26] found significantly lower levels of u-desmosine in COPD patients with lower FEV1. Another study by $\mathrm{Ma}$ et al. [9] could not demonstrate any correlation between $\mathrm{u}$-desmosine and various lung function parameters.

In this study we found that the elevation of b-desmosine levels were found in $69 \%$ of all COPD patients based on a cutoff of $0.30 \mathrm{ng} / \mathrm{ml}$. This cutoff value had a diagnostic sensitivity of $71 \%$ and specificity of $53 \%$ These findings suggest the elevations of desmosine are not specifically for COPD patients Our results are consistent with that of other researchers. Huang et al. [19] demonstrated that the elevations of b-desmosine level are specific to approximately $40 \%$ of COPD patients. Viglio et al. [25], and [18] they demonstrated that $\mathrm{u}$-desmosine and b-desmosine were much more pronounced in COPD subjects than in those without COPD (Table 1). However, Boutin et al. [26] found significantly lower levels of $\mathrm{u}$-desmosine in COPD patients. Explanations for the different results may be due to the different methods used, sample sizes variations and varying correction for other, potentially confounding, factors. Another explanation for inconsistent results between studies could be that the relationship between desmosine and lung function may be different in different populations depending on disease status and severity. However our results are in accord with the pathophysiology of COPD that involves neutrophil-driven inflammation, lung matrix degradation and increased desmosine release [27]. Although elastin is not specific component of the lungs but also serves an important function in the arteries, as a medium for pressure wave propagation to help blood flow, and is particularly abundant in large elastic blood vessels, such as the aorta. Elastin is also important in other tissues, such as elastic ligaments, the skin and the bladder. Therefore, it is possible that degradation from tissues other than the lung may have contributed to the associations seen in this study. However, since many of these tissues are affected in COPD due the systemic inflammation, this may also be relevant to the pathophysiology of the disease. It has also been estimated that the normal rate of lung elastin turnover accounts for only $19 \%$ of the desmosine excreted in urine [28].

\section{Conclusions}

This study has demonstrated that both u-desmosine or b-desmosine levels were significantly elevated among COPD patients. Also, u-desmosine and b-desmosine levels are correlated with COPD severity and some lung function parameters. This study suggests both u-desmosine or b-desmosine could be a useful biomarker in the diagnosis of COPD patients and to determine COPD severity.

\section{References}

1. Rabe KF, Hurd S, Anzueto A, Barnes PJ, Buist SA, et al. (2007) Global strategy for the diagnosis, management, and prevention of chronic obstructive pulmonary disease: GOLD executive summary. Am J Respir Crit Care Med 176: 532-555.

2. Barnes PJ, Shapiro SD, Pauwels RA (2003) Chronic obstructive pulmonary disease: molecular and cellular mechanisms. Eur Respir J 22: 672-688.

3. Luisetti M, Stolk J, ladarola P (2012) Desmosine, a biomarker for COPD: old and in the way. Eur Respir J 39: 797-798. 
Citation: Attia A, Abd El Halim A, Shebl E, Ali A (2013) Utility of Total Desmosine as Biomarker for Chronic Obstructive Pulmonary Disease Patients. J Pulm Respir Med 3: 152. doi:10.4172/2161-105X. 1000152

4. Foster JA, Curtiss SW (1990) The regulation of lung elastin synthesis. Am J Physiol 259: L13-23.

5. Turino GM, Ma S, Lin YY, Cantor JO, Luisetti M (2011) Matrix elastin: a promising biomarker for chronic obstructive pulmonary disease. Am J Respir Crit Care Med 184: 637-641.

6. Ma S, Lin YY, Tartell L, Turino GM (2009) The effect of tiotropium therapy on markers of elastin degradation in COPD. Respir Res 10: 12

7. Vestbo J, Rennard S (2010) Chronic obstructive pulmonary disease biomarker(s) for disease activity needed--urgently. Am J Respir Crit Care Med 182: 863-864.

8. Gaw A (2010) Desmosine/ isodesmosine in blood and urine. Biomarker qualification work shop. Bethesda, COPD Foundation.

9. Ma S, Lin YY, Turino GM (2007) Measurements of desmosine and isodesmosine by mass spectrometry in COPD. Chest 131: 1363-1371.

10. Stone PJ, Gottlieb DJ, O'Connor GT, Ciccolella DE, Breuer R, et al. (1995) Elastin and collagen degradation products in urine of smokers with and without chronic obstructive pulmonary disease. Am J Respir Crit Care Med 151: 952 959.

11. Qaseem A, Wilt TJ, Weinberger SE, Hanania NA, Criner G, et al. (2011) Diagnosis and management of stable chronic obstructive pulmonary disease: a clinical practice guideline update from the American College of Physicians American College of Chest Physicians, American Thoracic Society, and European Respiratory Society. Ann Intern Med 155: 179-191.

12. Evensen AE (2010) Management of COPD exacerbations. Am Fam Physician 81: $607-613$

13. Miller MR, Hankinson J, Brusasco V, Burgos F, Casaburi R, et al. (2005) Standardisation of spirometry. Eur Respir J 26: 319-338.

14. Albarbarawi O, Barton A, Lin Z, Takahashi E, Buddharaju A, et al. (2010) Measurement of urinary total desmosine and isodesmosine using isotopedilution liquid chromatography-tandem mass spectrometry. Anal Chem 82 : 3745-3750.

15. Luisetti M, Ma S, ladarola P, Stone PJ, Viglio S, et al. (2008) Desmosine as a biomarker of elastin degradation in COPD: current status and future directions. Eur Respir J 32: 1146-1157.
6. Lindberg CA, Engström G, de Verdier MG, Nihlén U, Anderson M, et al. (2012) Total desmosines in plasma and urine correlate with lung function. Eur Respir J 39: 839-845

17. Vrhovski B, Weiss AS (1998) Biochemistry of tropoelastin. Eur J Biochem 258 1-18.

18. Janssens JP, Pache JC, Nicod LP (1999) Physiological changes in respiratory function associated with ageing. Eur Respir J 13: 197-205.

19. Huang JT, Chaudhuri R, Albarbarawi O, Barton A, Grierson C, et al. (2012) Clinical validity of plasma and urinary desmosine as biomarkers for chronic obstructive pulmonary disease. Thorax 67: 502-508.

20. Selby C, Drost E, Wraith PK, MacNee W (1991) Neutrophil traffic through the lungs in man. Ann N Y Acad Sci 624: 353-354.

21. Stockley RA, Burnett D (1979) Alpha,-antitrypsin and leukocyte elastase in infected and noninfected sputum. Am Rev Respir Dis 120: 1081-1086.

22. Murphy TF, Sethi S (1992) Bacterial infection in chronic obstructive pulmonary disease. Am Rev Respir Dis 146: 1067-1083.

23. Mikami M, Llewellyn-Jones CG, Bayley D, Hill SL, Stockley RA (1998) The chemotactic activity of sputum from patients with bronchiectasis. Am J Respir Crit Care Med 157: 723-728.

24. Gottlieb DJ, Stone PJ, Sparrow D, Gale ME, Weiss ST, et al. (1996) Urinary desmosine excretion in smokers with and without rapid decline of lung function the Normative Aging Study. Am J Respir Crit Care Med 154: 1290-1295.

25. Viglio S, ladarola $P$, Lupi A, Trisolini R, Tinelli C, et al. (2000) MEKC of desmosine and isodesmosine in urine of chronic destructive lung disease patients. Eur Respir J 15: 1039-1045.

26. Boutin M, Berthelette C, Gervais FG, Scholand MB, Hoidal J, et al. (2009) Highsensitivity nanoLC-MS/MS analysis of urinary desmosine and isodesmosine. Anal Chem 81: 1881-1887.

27. Wright JL, Farmer SG, Churg A (2002) Synthetic serine elastase inhibitor reduces cigarette smoke-induced emphysema in guinea pigs. Am J Respir Crit Care Med 166: 954-960

28. Global Initiative for Chronic Obstructive Lung Disease. Global strategy for the diagnosis, management, and prevention of chronic obstructive pulmonary disease. 